\title{
Arquitetura e gênero: os desafios da formação profissional e do mercado de trabalho
}

Architecture and gender: professional training and labor market challenges

\section{Patrícia Falco Genovez 1}

Thamiris da Silva Duarte ${ }^{2}$

\begin{abstract}
RESUMO:
Essa pesquisa trata da questão de gênero tanto na formação profissional quanto no mercado de trabalho da Arquitetura. Nesse aspecto, abordamos elementos do processo histórico relacionados à questão de gênero, destacando os desafios enfrentados pelas mulheres tanto para chegarem à academia quanto para se estabelecerem na profissão.
\end{abstract}

PALAVRAS-CHAVE: arquitetura. Gênero. Formação Acadêmica. Mercado de Trabalho.

\section{ABSTRACT:}

This research deals with gender issue in the professional training and in the architecture job space as well. Having this in mind, we approach some dimensions of the historic process which relate to the gender issue, highlighting some challenges faced by women in their way to academy and in their professional settlement in job market.

KEY WORDS: Architecture. Gender. Academic Training. Job Market.

$$
* * *
$$

A construção dos gêneros articula-se de acordo com as hierarquias que a estrutura patriarcal traz consigo, e os papéis de gênero são uma definição sociocultural sobre aquilo que é apropriado para cada sexo. A cada papel corresponde um espaço: a casa e a cidade. (Montaner; Muxí, 2014, p. 197).

\footnotetext{
${ }_{1}^{1}$ Universidade Vale do Rio Doce. UNIVALE. Curso de Arquitetura. Professora Titular II, docente do Programa de Pós-Graduação Stricto Sensu Gestão Integrada do Território e pesquisadora do Núcleo de Estudos Históricos e Territoriais. Doutorado em História (UFF), Pós-doutorado em Teoria e Metodologia da História (UFMG). E-mail: patricia.genovez@univale.br.

2 Universidade Vale do Rio Doce. UNIVALE. Graduada em Arquitetura e Urbanismo. E-mail: duartesthamiris@gmail.com
} 


\section{Introdução}

A epígrafe escolhida para abrir esse artigo descreve bem como a Arquitetura e o Urbanismo, enquanto instrumentos de poder e agentes transformadores do ambiente público e privado são peças fundamentais na construção e configuração de um dado território, compreendido aqui de forma abrangente desde uma moradia a uma cidade. No desenvolvimento dessa área de conhecimento, coube aos arquitetos e urbanistas a capacidade de atender aos interesses coletivos, contribuindo para gerar qualidade de vida. Não obstante, tais transformações foram supostamente realizadas predominantemente por homens. Nesse sentido, o presente trabalho tem como objeto central refletir sobre a participação feminina nesse percurso.

A construção histórica da arquitetura e do urbanismo traz consigo uma dinâmica cultural atrelada aos papeis de gênero, encontrada também em outras áreas do conhecimento. Tais aspectos são um legado de uma sociedade que ainda mantém traços patriarcais. É certo que tal cenário se modificou ao longo das décadas por meio dos esforços femininos em busca de espaço. Porém, um olhar atento sob os principais destaques no campo arquitetônico nos trará a mente, provavelmente, em sua maioria, nomes masculinos. Em função desse cenário, cabe levantar o problema que norteará esse artigo: como se estabeleceu a questão do gênero na Arquitetura?

Preliminarmente, traçamos como hipótese que a presença feminina na Arquitetura, a princípio tímida, se iniciou nos lares, onde por um determinismo social, cabia à mulher o papel que lhe era imposto: o de mãe e cuidadora do lar. Tendo em vista nossa hipótese central, o objetivo desse artigo é elaborar de forma crítica, uma análise da trajetória feminina na arquitetura e no urbanismo, através do encontro de informações que tratam da atuação das mulheres e dos desafios encontrados na formação e no mercado de trabalho. Trataremos, portanto, da questão de gênero na arquitetura, abordando o contexto histórico dos séculos XIX e XX e as escolas de arquitetura, considerando a formação, o mercado de trabalho e a inserção feminina. 
Para realizar tal proposta optamos por uma pesquisa bibliográfica, elaborada por meio da definição de algumas palavras-chave: arquitetura e gênero, urbanismo e gênero e mulheres na arquitetura. Essa pesquisa foi feita na biblioteca da Univale e em sites de busca da Internet, tais como Google Acadêmico, Scielo e Biblioteca Digital Teses e Dissertações da USP. Inicialmente, essas buscas geraram o seguinte resultado: em cerca de 250 artigos apenas 50 deles se relacionam com as palavras-chave adotadas. Dentre tais artigos, destacaram-se inúmeros autores, dos quais realçaremos: Ana Gabriela Godinho Lima, Zaida Muxí e Josep Maria Montaner como os principais autores na discussão arquitetura, urbanismo e gênero.

Como se pode perceber, os trabalhos e estudos sobre gênero em arquitetura são poucos. Acreditamos que no momento atual, a discussão sobre o papel feminino, sua contribuição e desafios seja pertinente e deva ter sua relevância dentro da academia. Tal discussão pode e deve ser feita no âmbito da arquitetura e urbanismo visto que qualquer concepção projetual e prática passam por essa dimensão social.

\section{A relação arquitetura, urbanismo e o feminino}

$\mathrm{O}$ interesse pelo entendimento da casa, seu funcionamento, as primeiras formas construtivas e técnicas utilizadas pelo homem para sua construção, levam a crer que tal interesse se deve a relação existente entre o homem e o espaço que ele habita. Segundo Miguel (2002) a casa, que recebeu na história os diversos nomes de "cabanas, domus, castelos, villas, palazzos", é a representação mais elementar da arquitetura. Ela seria o que o autor chama de epiderme, ou seja, a terceira pele humana, uma vez que a roupa seria sua segunda proteção.

Sempre vista como local de proteção, refúgio e abrigo, a palavra "lar", atribuída a "casa" se relaciona com a palavra lareira. Lareira esta que remete ao fogo, sempre presente nas cabanas do homem primitivo, e que reúne ao seu redor todos os habitantes daquele espaço. Logo, se a casa é a pele individual 
do homem, o lar é a pele coletiva, que traz consigo todas as simbologias, memórias, proteção e união da família. (MIGUEL, 2002).

Segundo Mumford (1998) em todo o período neolítico, quando se fala em agricultura, as palavras "lar" e "mãe" são citadas. Elas seriam o centro da aldeia uma vez que esta girava em todo das casas e sepulturas dos mortos. As mulheres realizavam atividades importantes na aldeia. Eram elas que cuidavam dos jardins, manuseavam as enxadas, criaram os primeiros recipientes, entrelaçando cestas e os vasos de barro. Foram as responsáveis por criar espécies domésticas e nutritivas ao cruzarem espécies selvagens. A aldeia seria, portanto, considerada uma criação da mulher, o local de proteção e cuidado dos filhos. Assim, conforme Mumford,

\footnotetext{
Segurança, receptividade, proteção e nutrição - tais funções pertencem à mulher; tomam expressão estrutural em todas as partes da aldeia, na casa e no forno, no estábulo e no celeiro, no poço, no paiol, no silo, e dali passam à cidade, refletindo-se na muralha e no fosso e em todos os espaços internos, desde o átrio até o claustro. (...) Nos hieróglifos egípcios, 'casa' ou 'cidade' podem surgir como símbolos de 'mãe', como que a confirmar a semelhança da função formadora individual e coletiva. Ao lado disso, as estruturas mais primitivas - casas, aposentos, túmulos -, geralmente são redondas, lembrando o vaso original descrito no mito grego, que fora modelado no seio de Afrodite (MUMFORD, 1998, p. 19).
}

$\mathrm{Na}$ discussão sobre o sentido de lar/lareira/fogo, o tratado escrito por Vitruvius no século I a.C., o primeiro tratado de arquitetura, traz consigo a simbologia do fogo na construção da moradia. Em sua teoria, Vitruvius diz que a arquitetura encontra sua base na cabana, onde a família se protege do frio ao redor do fogo. "Para Vitruvio a cabana primitiva e o fogo revelam-se inseparáveis. É o fogo o elemento protoarquitetônico, sendo a partir dele que a arquitetura nasce como mito, rito e consciência.” (MIGUEL, 2002). Pouco depois os seres humanos aperfeiçoariam sua forma de criar e construir, transformando a cabana primitiva em arte. (MIGUEL, 2002; SCHETTINO, 2012). 
A sociedade primitiva levaria tempo para dominar as técnicas construtivas, sendo isso possível a partir da percepção da relação entre a natureza e o corpo. De acordo com Miguel (2002), para Vitruvio a humanidade imitava os ninhos dos pássaros, com barro e ramos de árvores. É, a partir do momento que a humanidade domina a técnica e suas habilidades se tornam mais aguçadas, inclusive produzindo arte, que esta será impressa em suas edificações.

Sendo a casa elemento influenciador tanto na vida do ser humano como na vida em sociedade, seu entendimento tem grande relevância nesse artigo. A casa não é somente um elemento, ela é concebida através de relações culturais. "Se a função passiva da casa é a provisão de um teto, sua finalidade é a criação de um entorno mais adequado ao modo de vida de um povo, em outras palavras, uma unidade espacial social." (SCHETTINO, 2012, p. 15). Sendo assim, a casa e o lar, atuam nos modos de vida da sociedade, bem como o externo e o cultural exercem influência sobre eles.

Partindo de tais considerações, indicaremos alguns traços sobre a presença feminina no lar, enfocando aspectos do cenário brasileiro, norteamericano e europeu. Nesse sentido, não só a mulher pertencente a elite brasileira, no fim do século XIX e início do século XX, mas a mulher pertencente a todas as demais camadas sociais vivia sob os padrões da chamada sociedade patriarcal. Aprisionada dentro do lar coube a essa mulher a influência sobre os espaços nas habitações. Não esquecendo as influências femininas das índias, portuguesas e africanas, é no período em questão, com um número maior de mulheres brancas nas moradias brasileiras que a casa tomará uma forma mais sólida. Portanto, apresentamos uma discussão sob a perspectiva da influência dessas mulheres brancas e de elite no lar (SCHETTINO, 2012).

\section{A presença feminina no lar e a economia doméstica: os cenários brasileiro, norte-americano e europeu}

Para se entender a participação feminina na arquitetura e no urbanismo, devemos considerar algumas transformações domésticas, pois foi 
no lar que as mulheres exerceram sua primeira influência. Os primeiros trabalhos acadêmicos relativos à casa brasileira surgiram no século XX e se concentram nas edificações utilizadas pela elite branca que habitava os centros urbanos. Porém, um século antes viajantes europeus produziram estudos. Nesse contexto, Santos (2005 apud SCHETTINO, 2012) definiu que a casa da elite brasileira do século XIX se destacava pela aparência uniforme das edificações, os lotes estreitos, a falta de instalações sanitárias, a presença de rótulas e muxarabis (figura 02), e a reclusão das mulheres.

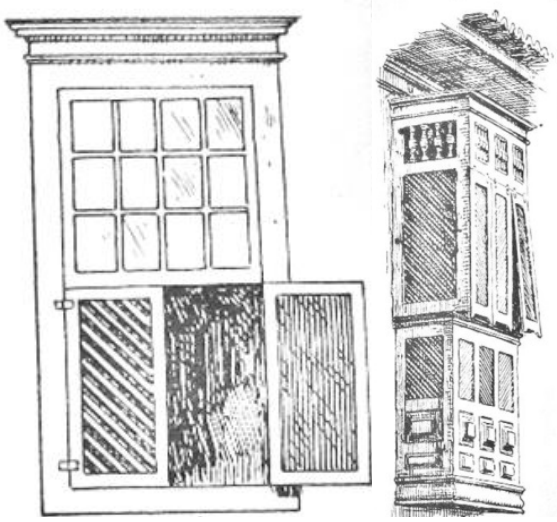

Figura 02- Janela em rótulas e muxarabiê sobreposto.

Fonte: RODRIGUES, 1979, p. 19.

Segundo Araújo (2006) esses estudos sobre a habitação, iniciado no século XX, abordavam os aspectos de estilo e forma, ficando as concepções espaciais sem um estudo direcionado. Desse modo, as questões sobre o uso dos cômodos, suas disposições e o que representavam não receberam destaque. Ressalte-se que a disposição arquitetônica e as mudanças ocorridas na estrutura dos lares da elite brasileira ocorreram ao longo do século XIX.

É no contexto monárquico que as casas perdem as rótulas e gelosias (onde as mulheres e crianças se escondiam juntamente com os escravos) ganhando porões altos e diferenciando-se do padrão arquitetônico do período colonial. Assim, seu interior não estava mais ao alcance dos olhares de quem passava na rua. Outra mudança foi a adoção de corredores internos e o surgimento dos recuos no lote. Contudo, a principal modificação ocorreu na distribuição dos cômodos, a partir do momento em que há uma valorização do 
lar em detrimento dos ambientes públicos. Estabelece-se, assim, uma nova significação para o público e o privado. Além disso, houve a definição da casa em três setores: o público, o íntimo e o de serviços, nos fundos (ROLNIK, 1985).

Para Araújo (2006) foi a partir de tal distribuição que se iniciou a discriminação social e o reforço das diferenças das relações de gênero. Ainda segundo ela, a divisão da casa em setores social, íntimo e de serviço, ao qual chama de "modelo tripartite" passou a ser entendida dessa forma a partir da construção da arquitetura enquanto disciplina. "Sua construção certamente envolve campos variados do conhecimento e de práticas políticas, econômicas, sociais e culturais." (ARAÚJO, 2006, p. 16). Nesse aspecto, a obra de Michel Foucault On Other Spaces, e o conceito de heterotopia, caracterizando os lugares e ambientes heterotópicos (o teatro, o museu, o asilo, a prisão, o cemitério, a igreja, o bordel, a colônia) como aqueles espaços que nos tiram da mesmice da vida cotidiana. O fato de Foucault não retratar os lugares de lazer, de trabalho, o playground, a rua e a casa como heterotopias, o leva a exclui as crianças e as mulheres; o que acaba sendo alvo de críticas por parte dos estudos relacionados à questão de gênero. (ARAÚJO, 2006).

Importante para a compreensão nas mudanças ocorridas nos aspectos formais da casa é a formação da família nesse período, conforme Schettino (2012, p. 22),

A classe dominante do final do século XIX tem sua origem na primeira metade do século, quando os filhos das famílias mais abastadas eram enviados a Portugal para estudar, especialmente, em Coimbra. Esse processo se manteve em condições muito semelhantes depois da independência quando os futuros membros da alta sociedade estudavam nas duas escolas de direito nacionais, uma localizada em São Paulo e outra em Recife, onde se formava toda a burocracia do Estado: advogados, deputados, senadores e diplomatas.

No Brasil, as famílias pertencentes às elites foram os principais agentes transformadores tanto da vida social, como da arquitetura. As 
diferenças nas relações de gênero foram fortalecidas tanto pela distribuição espacial da casa como pela formação do seio familiar (SCHETTINO, 2012, p. 22).

Cavalcante et al (2015), citam Mary del Priore em seu livro Ao Sul do Corpo (1993), para retratarem a mulher do século XIX. A mulher pertencia o controle sobre o homem e sobre a família. Contextualizada no período da colonização, a sociedade brasileira era fortemente influenciada pela coroa portuguesa e pela Igreja. Logo, essas duas instituições viram na mulher uma forma de conquistar terras e manter a autoridade sobre a população. Sendo assim a mulher era o que a autora chama de "ponto de controle". Essa herança colonial sobrevive no século XIX quando os diferentes papeis atribuídos a homens e mulheres seriam reforçados com as visões da Igreja e da Medicina sobre o corpo feminino. A relação era de diferença entre os sexos masculino e feminino (CAVALCANTE et al, 2015).

A vida pública feminina, em boa parte dos lares da elite brasileira, no século XIX, praticamente inexistia. A mulher era vigiada e controlada, sendo restrita sua entrada em certos locais. Sua imagem na sociedade estava associada ao seu recato e papel de esposa e mãe. Segundo Schettino (2012, apud HOMEM, 1996), no século XIX, a mulher realizava trabalhos leves, possuía pouca instrução e estava presa dentro de uma casa de aparência rígida e triste. Não recebia as visitas, não se sentava à mesa com desconhecidos e não saía à rua sozinha, estando sempre acompanhada de seu marido ou outro familiar. Somente observava os passantes através da rótula. Os espaços internos eram a área de circulação das mulheres (CAVALCANTE et al, 2015; SCHETTINO, 2012).

Deve-se ressaltar que esse comportamento era característico das mulheres de classe alta. Entretanto, nem todas as mulheres poderiam passar o dia somente cuidando dos filhos e das tarefas domésticas. "Brancas pobres, escravas e forras precisavam garantir o sustento da família e transitavam pelas ruas de maior movimento livremente, sem despertar nenhuma estranheza aos passantes." (SCHETTINO, 2012, p. 21). Como consequência, as mulheres lavadeiras, costureiras e rendeiras, ganharam fama 
preconceituosa e mal falada nas ruas. Por isso, uma mulher não deveria ganhar dinheiro para sustentar a casa e sim, o homem. Logo, a mulher pertencente à classe mais alta, mantida mais reclusa, exerceu maior influência na disposição espacial das residências (CAVALCANTE et al, 2015).

Para a mulher, o espaço público significava repressão e controle. Seus passos e atos eram constantemente vigiados. Aliado a isto, a nova organização da sociedade burguesa determinou os papéis masculino e feminino. Ao homem, cabia o sustento familiar, enquanto a mulher era responsável por cuidar da casa e da família, garantindo a felicidade dos filhos e do marido.

Os papeis atribuídos aos sexos delimitam o que a eles é apropriado nos espaços públicos e privados. De acordo com Montaner e Muxí (2014), há uma conceituação básica para toda a arquitetura e a cidade, que permanece em evolução constante na sociedade, que é justamente essa construção e delimitação: as esferas do público e do privado. O espaço interior e privado se relaciona com a funcionalidade, a maneira como se habita o espaço, sendo a mulher sua principal usuária. A mulher apresentaria maior obstinação pelo espaço privado, o homem por sua vez, o renegaria. A rua, o espaço exterior, é o seu lugar de pertencimento, seu espaço natural. (MACHADO, 2011).

A mulher vivia o ambiente exterior por meio das experiências do marido, observando a rua através da janela. Fadada a esse cotidiano, vivia uma realidade que não lhe pertencia, uma realidade segundo a vivência de outras pessoas. A esse tipo de construção corresponde uma dada relação do público versus o privado, instaurada nas moradias. Ainda segundo os autores, a modernidade trouxe consigo uma estrutura social em que os papeis de gênero deixaram a mulher à margem, reclusa nesse ambiente privado. Mesmo no lar, em seu local de designo, foi possível a ela desfrutar de alguma liberdade, pois vivia sobre as limitações do sistema patriarcal (MONTANER; MUXÍ, 2014).

Para o homem o que realmente importava em sua casa era sua imagem externa, a ele o interior pouco tinha de relevante. A casa significa poder, um objeto, a imagem pública que se tinha sobre ele enquanto proprietário do imóvel e chefe de sua família. Já para a mulher, a casa representava outra 
realidade. Era entre aquelas paredes que ela passava a maior parte de seu tempo, logo, era natural que a imagem daquele interior lhe fosse familiar e agradável (MACHADO, 2011).

Refletindo sobre a relação entre mulher, arquitetura e urbanismo, podemos pensar que o espaço interno da casa, atribuído à mulher, deu a ela entrada no mundo arquitetônico bem antes do que sua entrada no mundo acadêmico. O conhecimento sobre a realização das tarefas, o espaço ideal entre um mobiliário e outro, ou mesmo o tamanho desse mobiliário era pensado por ela e para ela. Quando o homem se volta para o espaço externo da casa, é fácil para ele a percepção e compreensão do urbano, ao passo que para a mulher essa compreensão se daria mais tardiamente e sob outra perspectiva.

Detentora desse poder de transformação do ambiente interno da casa, o mobiliário da casa é repensado para ela. É nesse momento que a mulher toma para si o apego ao detalhe, que seria característico de seu gênero, uma vez que o homem, diante de tais detalhes e complexidades, não teria o mesmo apreço que o gênero feminino. O mobiliário passa a ser uma característica da mulher; a ela era direcionado o elemento detalhista, o móvel (MACHADO, 2011).

Outras transformações, como as novas disposições dos cômodos e o grau de privacidade atribuído a eles aparecem ao longo do tempo. A partir da introdução do conceito de privacidade, a mulher se torna responsável por definir o conforto. Contudo, as mudanças na vida social no decorrer do final do século XIX e XX contribuíram para uma modificação no espaço residencial, levando a novos ambientes e disposições espaciais. $\mathrm{O}$ conceito de privacidade, antes ligado somente à mulher, se transfere para o lar. A casa passa a ser vista como ambiente de conforto, intimidade, privacidade e domesticidade (SCHETTINO, 2012).

A busca feminina pela eficiência na realização das tarefas a elevaria a um passo a frente. A evolução dos equipamentos e eletrodomésticos no final do século XIX e início do século XX, conferem o conforto ao ambiente doméstico. "A partir da década de 1920, o conforto trazido por esses 
equipamentos e tecnologias tornou-se mais acessível, a princípio nos Estados Unidos e mais tarde na Europa, por causa do desenvolvimento da indústria." (SCHETTINO, 2012, p 75). Era esse contexto mais amplo que, de certa forma, temos que considerar para compreendermos o cotidiano feminino em fins do século XIX e nas primeiras décadas do século XX, no Brasil.

Em resumo, vimos que sob esse longo contexto que transitou entre o período colonial e o monárquico, surgiu a separação entre espaço feminino e masculino e com ela o adensamento da discriminação social e de gênero. A partir do século XIX, com as transformações ocorridas na casa, com a valorização da privacidade e com as novas divisões espaciais, a mulher se vê confinada a um papel social atribuído a ela por questões históricas, sociais, religiosas, políticas e até mesmo por um determinismo biológico.

Nesse cenário alargado, cabe realçar alguns elementos que emergem da consolidação da Revolução Industrial no século XIX, dentre eles: as mudanças sociais e urbanas que levaram a adoção de novas posturas, especialmente, de setores conservadores religiosos e moralistas, inspirados nos ideais higienistas e progressistas, que impuseram costumes éticos e morais à vida individual e coletiva. "A solução para a moradia operária majoritária e estudada pela historiografia consistiu em uma redução ao mínimo imprescindível da moradia burguesa, com suas hierarquias e suas divisões espaciais, que obedeciam e reforçavam os papéis tradicionais dos gêneros.” (MONTANER e MUXÍ, 2014, p. 68).

O sistema de produção em série, característico da Revolução Industrial, composto pela divisão das atividades e pelos papeis sociais específicos, gerava funcionalidade e especialização nas linhas de montagem das fábricas. Essa distribuição de papeis sociais e a funcionalidade chegou aos ambientes domésticos. Segundo Montaner e Muxí (2014) essa nova ordem possibilitou uma visão diferente sob as tarefas e atividades realizadas pelas mulheres no lar.

Nos Estados Unidos e Europa, o uso de empregadas domésticas havia caído intensamente, pois o trabalho era pesado e não valorizado. As mulheres que precisavam trabalhar preferiam o trabalho fabril ao trabalho nas casas 
burguesas. Após a década de 1900, com o avanço dos eletrodomésticos, o trabalho doméstico foi facilitado. As esposas americanas vendo que as atividades foram facilitadas, passaram a exercer as funções domésticas. O que se seguiu posteriormente foi o início de produções teóricas sobre a administração do lar, na busca de aperfeiçoar as tarefas em prol da mulher. O conforto na realização das tarefas domésticas foi a grande inovação. Surge a preocupação em diminuir o tempo gasto na realização das tarefas. (SCHETTINO, 2012).

A essas propostas e pensamentos sobre o funcionamento do lar e a melhoria na execução das atividades, se denominaria economia doméstica, voltada para

O estudo da casa, especialmente da cozinha, como um espaço de produção taylorista onde a linha de montagem é formada por uma única operária, que realiza de maneira eficiente, coordenada e pautada as diferentes fases dessa linha. Tem início um processo de conhecimento científico das tarefas do lar, especialmente daquelas que se referem à preparação de alimentos: medem-se alturas, distâncias e percursos de modo a torna-los mais eficientes e científicos (este adjetivo é de grande importância) (MONTANER e MUXÍ, 2014, p. 70-71).

É interessante notar que a chamada economia doméstica apenas mascarou a realidade e fazendo com que as mulheres se sentissem bem com as tarefas executadas diariamente, impostas pelos papeis de gêneros a elas atribuídos.

Ao longo da história moderna, tentou-se equiparar a casa, especialmente a cozinha, a um laboratório, um espaço especial com o qual a mulher pode ficar satisfeita e se sentir orgulhosa. Trata-se de travestir uma obrigação do papel de gênero em algo desejado, equiparável ao trabalho de uma fábrica (MONTANER e MUXÍ, 2014, p. 71). 
Paralelo a esse contexto, segundo Fontes e Medeiros (2015), o campo profissional arquitetônico e urbanístico era essencialmente masculino. Às mulheres coube a produção teórica, pois tal atividade era vista como aceitável para o sexo feminino. Lima (2012) afirma que os trabalhos domésticos se iniciaram na Europa e nos Estados Unidos por três motivos: a escrita era um trabalho aceito para as mulheres, pois podiam fazê-lo dentro do lar; não encontravam competição direta com homens nessa atividade; e o terceiro e mais evidente é o fato de que as mulheres conheciam melhor o lar, as tarefas e seu funcionamento.

De acordo com Coelho et al. (2015), a atuação feminina na arquitetura sofreu grande influência da sociedade industrial do século XIX. As mulheres desse período estavam envolvidas com trabalhos de enfermagem e serviço social, vistos como um tipo de trabalho comunitário, onde elas contribuíam para a sociedade assim como contribuíam no lar. Essa contribuição dada à comunidade era tida como uma expansão das obrigações domésticas. Elas só teriam um primeiro contato com a arquitetura através da economia doméstica, buscando soluções para o lar. As autoras citam o conceito criado por Kate Gannet Wells, filantropa e escritora norte americana, chamado mulher transitória. Dessa forma, a mulher transitória do século XIX, de acordo com Wells, era cheia de inquietações e pensamentos próprios, buscava um propósito que ia além do que a elas era imposto socialmente. As mulheres encontrariam na arquitetura uma forma de solucionar os problemas sociais gerados por um ambientes insalubres.

Em suma, a mulher norte-americana e europeia se viu inserida em um novo contexto: a contratação de empregados domésticos passou a ser vista como desnecessária, os novos aparelhos como aspirador de pó, máquina de lavar e secar roupa, e ferro elétrico, etc. permitiam a realização rápida das tarefas. "Essa posição era defendida por grupos feministas como o Material Feminist, que pregavam a coletivização dos serviços domésticos, com a criação de cozinhas coletivas, a remuneração do trabalho da dona-de-casa e a transformação espacial e material das casas.” (SILVA, 2008 apud SCHETTINO, 2012, p. 75). 
$\mathrm{O}$ avanço experimentado no século $\mathrm{XX}$ teve alguns destaques vinculados ainda ao século XIX, dentre os quais, a norte americana Catherine Beecher, que escreveu em 1841 o primeiro tratado sobre economia doméstica, A treatise on domestic economy for the use of young ladies at home and at school (Tratado de economia doméstica para ser usado por moças em casa e na escola). Segundo Schettino (2012), em suas obras, Beecher escrevia não apenas sobre a administração do lar, mas também sobre a construção das casas, priorizando a saúde, a conveniência e o conforto dos projetos residenciais, sem enfatizar a questão do estilo arquitetônico (SCHETTINO, 2012, p. 76).

Em 1869, Beecher se juntaria a sua irmã Harriet Beecher Stowe publicando o mesmo tratado numa versão mais completa, intitulado The American Woman's Home, propondo uma estrutura de casa onde a cozinha era o elemento arquitetônico principal. Elas "Propunham cozinhas semelhantes às linhas de montagem das fábricas com bancadas de trabalho contínuas, à altura da cintura e com armários." (SCHETTINO, 2012; p. 76). Outro aspecto, segundo Oliveira e Mont'Alvão (2010) é que, pela primeira vez, um projeto aliava design à recente ergonomia, as prateleiras na parte superior das paredes, os locais criados para armazenar alimentos e a amplitude de espaço para trabalhar completavam o ambiente. A figura 03 mostra o modelo de cozinha proposto por elas.

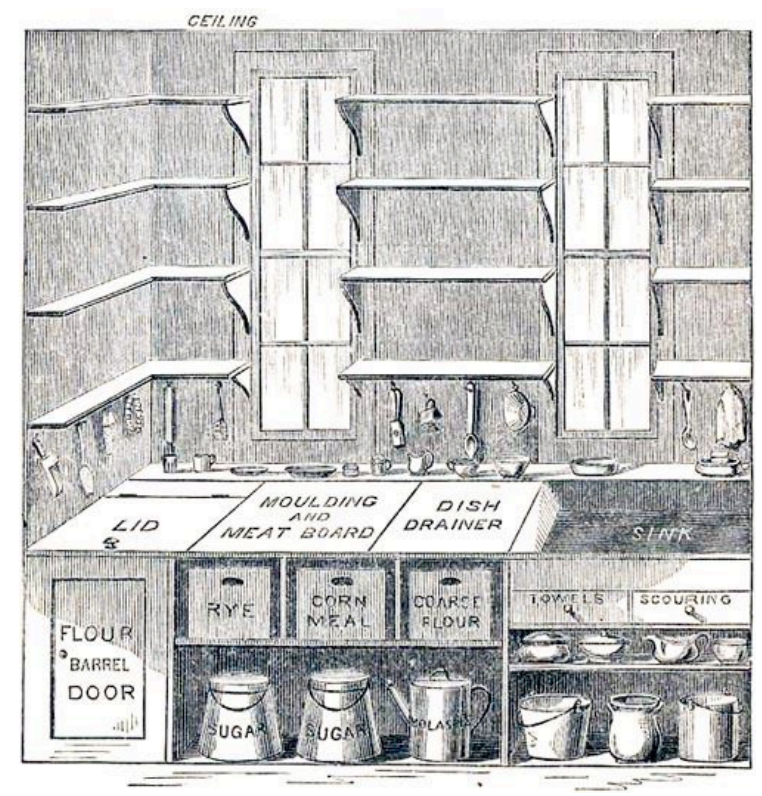

Figura 03 - Pia, armário, prateleiras e fogão em 
The American Woman's

Home, por Catherine e Harriet Beecher.

Fonte: OLIVEIRA e MONT'ALVÃO, 2012.

O diferencial nos seus trabalhos e nos trabalhos de outras mulheres estava na abordagem. Enquanto os exemplares masculinos ocupavam-se da estética, voltados para a moda e ornamentação, os femininos focavam no funcionamento da casa. Nesse período, os livros sobre os espaços residenciais escritos por homens não se preocupavam com as atividades domésticas femininas, pois, para eles, tais funções deveriam ser realizadas por empregados, portanto não precisavam ser facilitadas. A partir da discussão feita pelas irmãs Beecher, novas publicações surgiriam, emergindo discussões sobre o abolicionismo, o uso de empregados domésticos e questões de gênero (LIMA, 2012; SCHETTINO, 2012).

O foco das irmãs Beecher estava voltado para a usuária da casa, a mulher. A proposta se diferenciava do olhar masculino e seus projetos eram distintos dos trabalhos elaborados por homens. Afirmavam que "Não há um aspecto da economia doméstica que diga respeito à saúde e ao conforto diário das mulheres americanas mais do que a construção adequada das casas." (LIMA, 2012; apud BEECHER apud RYBBCZYNSKI, 2002: 166). Essas publicações foram veiculadas para as camadas médias americanas, pois as classes privilegiadas não se preocupavam em aumentar a eficiência nas tarefas domésticas, visto que eram cumpridas por criadas, não por donas de casa (SCHETTINO, 2012).

Depois de Beecher outras mulheres começariam a escrever sobre economia doméstica e a otimização das tarefas do lar. Christine Frederick se manifestou contra a contratação de empregadas domésticas, afirmando que essas seriam o maior empecilho na administração do lar, uma vez que, geralmente, eram meninas pobres e sem instrução, que não queriam manusear os aparelhos domésticos, agora mais tecnológicos. Frederick foi uma das primeiras mulheres a pensar no lar de modo científico, em sua eficiência científica. Ela iniciaria uma pesquisa a partir da observação das tarefas diárias executadas pelas mulheres e nos detalhes de seus movimentos. É nesse período, no início do século XX, que o conhecimento científico sobre o 
lar ganhara força, surgindo revistas direcionadas à casa. Frederick publicou suas ideias no periódico The Ladie's Home Journal, direcionado ao público feminino (LIMA, 2010; SCHETTINO, 2012).

Um aspecto importante sobre essas produções femininas sobre o lar é que as autoras viam com desconfiança os arquitetos, tanto é que se autodenominaram "engenheiras domésticas" e não "arquitetas domésticas". Nos Estados Unidos, os engenheiros participaram ativamente do processo, estudando novas formas espaciais e movimentos necessários para a execução das tarefas. Porém, na Europa, foram os arquitetos quem mais contribuíram (SCHETTINO, 2012).

Segundo Lima (2012), durante o avanço do século XIX, os trabalhos femininos tornavam-se cada vez mais bem embasados. Os trabalhos masculinos sobre a temática habitacional também aumentaram. Os arquitetos debatiam assuntos como higiene, espaços eficientes para o trabalho doméstico e modos de racionalizar as atividades. Quando se atinge o século $\mathrm{XX}$, todas essas posturas iriam contribuir para mudanças na vida feminina. A mulher começa redimensionar seu papel dentro da sociedade, iniciando um caminho para atingir sua independência. Elas passam a ser vistas como inteligentes, educadas e capazes de contribuírem para a sociedade além dos valores tradicionais do cuidado com o lar e os filhos. (LIMA, 2012).

Enquanto na Europa e Estados Unidos alcançava-se o progresso gradativamente, na América Latina o cenário era outro. Mais precisamente no Brasil, durante o século XIX, conforme vimos, ainda se vivia o período escravocrata. As mulheres que aqui poderiam usufruir dos avanços dos eletrodomésticos ou escrever sobre a economia doméstica, por possuírem cultura e instrução, eram as pertencentes às classes superiores. Logo, eram elas que tinham empregados domésticos em casa. E as mulheres de classe baixa e sem instrução eram as que precisavam trabalhar para o sustento da família. (FONTES e MEDEIROS, 2015).

A maneira encontrada pelas mulheres para escrever sobre teoria arquitetônica na América Latina, se dá de modo diferente da ocorrida na Europa e Estados Unidos. Lima (2012) irá discorrer sobre os fatores 
explicativos de tal questão, ao afirmar que no fim do século XIX e início do XX, nos países europeus e na América do Norte, a dificuldade em se encontrar empregados domésticos, levaram as mulheres de classe média a assumir posturas e iniciativas.

Dessa forma, enquanto nos Estado Unidos, Beecher discutia tais questões sobre a casa, no Brasil, ainda regido pelo regime escravocrata, sequer pensava-se nas atividades do lar. De acordo com Lima (2012), mesmo após a abolição, o que ela chama de "abismo social" reinava sobre o ambiente doméstico. Portanto, as produções femininas latino americanas voltadas para a economia doméstica não existiram. Entretanto, no que dizem respeito às produções feministas, estas ganharam cada vez mais força no século XX no Brasil, mais precisamente a partir da década de 1960.

A situação dicotômica que se instaura no Brasil e em toda América Latina, como afirma Lima (2012), é causada pelo quadro econômico das famílias. As mulheres das classes mais altas possuíam educação e cultura, logo tinham capacidade de discutir, propor, pensar sobre o ambiente doméstico. Entretanto, eram justamente essas mulheres que tinham empregados em casas. A imersão feminina no mundo da escrita proporcionou sua entrada no mundo acadêmico. Entretanto, a inserção nas universidades não se deu de modo fácil. No transcorrer do século XX, especialmente entre as décadas de 1930 e 1980, como declaram Fontes e Medeiros (2015), os governos brasileiros incentivariam a chamada Arquitetura Moderna. No Brasil, a entrada da mulher na arquitetura estaria contextualizada com os ideais do movimento. Veremos no próximo item como se deu a inserção feminina nas escolas de arquitetura na Europa, Estados Unidos e no Brasil.

\section{As escolas de arquitetura e gênero: formação e mercado de trabalho}

Atualmente há um número considerável de mulheres debatendo sobre a história, a crítica e a teoria arquitetônica. Contudo, de acordo com Sá (2010), as pesquisas, discussões, palestras e publicações sobre a temática da mulher na arquitetura evoluíram aos poucos. Na Europa e Estados Unidos as 
feministas começaram a produzir impacto na crítica literária na década de 60. No campo arquitetônico as discussões de gênero chegaram por volta das décadas de 70 e 80. No Brasil, as produções com a temática ainda são iniciais, seguindo uma linha feminista, por vezes jornalística, estatística ou antropológica (LIMA, 2012; SÁ, 2010).

O cenário atual da mulher nas escolas de arquitetura é diferente de seu quadro inicial. Se hoje elas representam um valor igualitário ou maior do que os homens nas salas de aula, antes passaram por obstáculos dentro das universidades. Ressaltamos a escassez bibliográfica sobre a inserção feminina nas escolas brasileiras e os reduzidos estudos que refletem sobre a inserção nas escolas estrangeiras.

\subsection{As mulheres na escola de arquitetura}

Na famosa escola alemã Bauhaus, de Walter Gropius, “[...] a [...] notável escola alemã de artes, ofícios e arquitetura que, tendo funcionado entre 1919 e 1933, excluiu deliberadamente as mulheres do aprendizado arquitetônico”. (LIMA, 2006, p. 1479). Em contrapartida, na escola norte americana de Cambridge, que funcionou de 1915 a 1942, as mulheres encontraram ensino direcionado a elas (LIMA, 2006).

A Bauhaus, fundada em 1919, na cidade de Weimar, foi de grande importância na construção pedagógica das artes e da arquitetura no século XX. As obras produzidas e as atividades variadas influenciaram e fomentaram o meio arquitetônico e artístico, marcando o início do design moderno no mundo. Na primeira metade do século XX a arquitetura se livrou da ornamentação e da decoração, visando a praticidade. As edificações teriam agora contornos claros e formas simples (ARQUITETURA E URBANIDADES, 2011; LIMA, 2006).

Seu diretor Walter Gropius, inspirado nos ideais do movimento moderno acreditava numa nova construção do homem, a qual denominava-se a construção do homem moderno. Baseado nesse ideal, a Bauhaus tornou-se um meio poderoso para implantar esse projeto. Seus projetos arquitetônicos 
deveriam presar pela funcionalidade, não comportando enfeites supérfluos (ARQUITETURA E URBANIDADES, 2011; LIMA, 2006; SÁ, 2010).

Os professores e alunos da escola passavam uma imagem utópica do real sistema, no qual as mulheres estavam, na realidade, em segundo plano. No primeiro discurso direcionado aos alunos, Gropius buscava popularizar o design e afirmou que as mulheres possuíam os mesmos direitos e obrigações que os homens, porém, na prática, esse discurso era infundado (LIMA, 2006; SÁ, 2010).

Em setembro de 1920, o mesmo Gropius sugeriria ao Conselho dos Mestres, que deliberava sobre as atividades da Bauhaus, que 'a seleção devia ser mais rigorosa desde o princípio, particularmente no caso do sexo feminino, que contava já com um número excessivo' [GROPIUS in: Droste, 1994, p. 40 apud LIMA, (2006), p. 1481].

Magdalena Droste em sua obra Bauhaus (1994), afirma que para Gropius "nenhuma mulher deveria ser admitida para estudar arquitetura" e sua entrada na Bauhaus deveria ser dificultada. Quando uma mulher conseguia ser admitida era enviada para a tecelagem. Em sua visão o que as mulheres produziam era rejeitado pelos homens sendo visto como feminino ou artesanal. O pensamento masculino temia a adoção de uma tendência decorativa na escola e seu ideal de progresso e construção do homem moderno, estava em perigo (LIMA, 2006; SÁ, 2010).

Lima (2006) atenta para o fato de que, o comportamento diferente, dado aos estudantes, baseado em seu gênero, teria comprometido a construção de identidade desses sujeitos. Para ela, o comportamento distinto recebido por homens e mulheres tangenciava uma questão de representatividade. $\mathrm{O}$ tratamento desigual dos alunos a visão que esses alunos tinham de si.

A Cambridge School (1915-1942), por sua vez, dedicou-se ao ensino de arquitetura para mulheres. Sua formação se deu quando uma estudante que desejava se formar em paisagismo descobriu que mulheres não eram admitidas na Havard Graduate School of Landscape Architecture. O então diretor James Sturgis Pray pediu a Henry Atherton Frost que fosse tutor da estudante no período de um ano (LIMA, 2006). 
Inicialmente Henry Frost questionou se a experiência traria resultados positivos, mas aceitou a proposta lecionando em seu escritório para seis alunas. Para sua surpresa, tempo depois, outras alunas buscaram aprendizado. Desse modo, iniciou-se a Escola de Arquitetura e Paisagismo de Cambridge, a primeira e única escola de arquitetura voltada para mulheres nos Estados Unidos (COELHO et al, 2015; LIMA, 2006).

O currículo da escola era voltado para a "arquitetura doméstica" com a decoração de interiores. Era constituído por três partes, Design, Construção e Desenho Livre. Além disso, a escola uniu o ensino de arquitetura e paisagismo, que até então eram disciplinas diferentes. A escola pretendia não apenas ensinar arquitetura e urbanismo a suas alunas, mas propor um desafio intelectual, garantindo a elas sagacidade para a carreira profissional. Anos depois, a escola de Cambridge ficou conhecida por encaminhar arquitetas ao mercado e por formar profissionais de destaque com projetos de design inovador (COELHO et al, 2015).

Frost, em seus escritos, observava a facilidade das mulheres no desenho delicado e sua percepção na cor e no detalhe. Para ele, as mulheres deveriam se dedicar a arquitetura doméstica e os homens a projetos monumentais. É interessante notar aqui a gradual mudança atribuída ao papel feminino, embora mantendo-se uma questão de gênero. "A possibilidade de uma mulher trabalhar na arquitetura doméstica parecia, portanto, muito mais razoável"(Lima, 2006; p. 1485).

$\mathrm{O}$ fato é que as estudantes não ficaram restritas à arquitetura doméstica, recebendo apoio para desenvolverem projetos variados de escolas, pavilhões, hospitais, restaurantes e projetos urbanísticos. Frost se mostrava surpreso ao descobrir que as mulheres possuíam capacidade enorme para solução dos mais variados temas arquitetônicos, chegando a admitir que não era somente arquitetura doméstica que se ensinava em Cambridge. Contudo, em seus estudos Henry Frost ainda demonstrava que a produção masculina era superior à produção feminina. Ele teria assumido tal postura, pois ainda lecionava em Havard, respeitando os ideais da escola para manter uma boa relação com os outros professores (LIMA, 2006; SÁ, 2010). 
Em termos do contexto brasileiro podemos considerar que o primeiro curso de Arquitetura surgiu no século XIX, com o decreto de Dom João VI, de 12 de agosto de 1816, que estipulava a criação da Escola Real de Ciências, Artes e Ofícios, resultado da Missão Artística Francesa no Brasil. Tratava-se de um marco para o desenvolvimento das artes no Brasil. A missão chegou a solo nacional no dia 25 de março de 1816 com o objetivo principal de iniciar o estudo regular de artes (CAU/RJ, 2016; IPHAN; MinC, 2016).

O contexto histórico da Missão Artística Francesa se deu com a derrota de Napoleão em Waterloo, em 1815. Os artistas franceses se viram impedidos de continuarem o trabalho que exerciam. Muitos buscaram então, outros meios de realizarem suas atividades, como Joaquim Lebreton, secretário perpétuo da Classe de Belas Artes do Instituto da França e administrador das Obras de Arte no Museu do Louvre (CAMARGO, 2012).

Lebreton, ao saber dos rumores acerca do progresso artístico na América Portuguesa, foi ao representante de Portugal em Paris, Dom Pedro José Joaquim Vito de Menezes Coutinho, o Marquês de Marialva, propor a criação de uma Academia de Belas Artes no Brasil. Antônio de Araújo e Azevedo, o Conde da Barca e então ministro de Dom João VI, via com bons olhos a propagação artística na colônia. Para ele a presença de cientistas e intelectuais no Novo Mundo possibilitaria o progresso da civilização. Essa era também a visão dos idealizadores da missão francesa, onde se objetivava transformar e civilizar o Rio de Janeiro na capital do Reino Unido de Portugal, Brasil e Algarves (CAMARGO, 2012; TREVISAN, 2007).

$\mathrm{O}$ primeiro curso de Arquitetura foi, portanto, o de Arquitetura Imperial de Belas Artes do Rio de Janeiro, o único do Brasil por mais de cinquenta anos. Era uma instituição pública que recebia estudantes de origem modesta desde sua criação, em 1826." (SALVATORI, 2008, p. 52). Em 1959, a escola recebeu outro nome, o de Escola Nacional de Belas Artes (ENBA). Durante o século XIX formou poucos arquitetos, e no início do século $\mathrm{XX}$ passou a receber estudantes de classes mais abastadas, que viam na profissão um futuro visionário economicamente. No fim do XIX já era possível 
perceber o surgimento de outros cursos de arquitetura em escolas de Engenharia e Belas Artes nas principais cidades do país (SALVATORI, 2008).

Os cursos de arquitetura no Brasil se consolidaram, portanto, de forma tardia em comparação a outros países. A inserção masculina como arquiteto no mercado se deu vagarosamente e a feminina, então, foi ainda mais lenta. Entretanto, para Sá (2010), apesar das dificuldades culturais impostas pelos papeis de gênero, não houve em momento algum na história da entrada feminina nas universidades de arquitetura brasileiras, uma restrição explícita (SÁ, 2010).

O ensino arquitetônico no Brasil e na América Latina no século XX se mistura com o movimento introduzido nos Estados Unidos pelos europeus Walter Gropius e Mies Van der Rohe, o Movimento Moderno. Os ideais do Modernismo chegaram aqui através de estudantes e arquitetos que tinham tido contato com as escolas de arquiteturas das potências mundiais e, ao retornarem, difundiam o aprendizado por meio de seus projetos, livros, publicações e congressos. No Brasil, foi o caso da engenheira e urbanista Carmem Portinho que fundou a União Universitária Feminina e ajudou na criação da Associação Brasileira de Arquitetas e Engenheiras (ABEA); e, da arquiteta Lina Bo Bardi, tendo o Museu de Arte de São Paulo (MASP) como seu mais conhecido trabalho (ARQUITETAS INVISÍVEIS, 2015; LIMA, 2012).

$\mathrm{Na}$ década de 30, verifica-se uma tendência arquitetônica que misturava o colonial, as tradições vernáculas e novas formas do Movimento Moderno. De acordo com Lima (2012), o movimento modernista trouxa para a América Latina um discurso com novas ideologias, símbolos e procedimentos que norteariam a nova arquitetura e o novo urbanismo. Logo, surgem novos métodos e estratégias na atuação do profissional arquiteto, novas maneiras de se pensar o espaço público e privado e um modo diferente em se pensar a função do edifício (LIMA, 2012).

Segundo Salvatori (2008), a propagação dos cursos de arquitetura no Brasil está relacionada aos projetos do governo na busca da modernidade, à urbanização e ao crescimento das populações urbanas: "A história da 
profissão no Brasil está relacionada tanto com a evolução do pensamento arquitetônico e à mudança da visão filosófica do mundo, como com o crescimento das populações urbanas, o surgimento de novas classes sociais e à progressiva globalização da economia." (SALVATORI, 2008; p. 53).

A história dos cursos de arquitetura no Brasil está, portanto, diretamente ligada à nova mentalidade vivida no país. Na década de 1930, quando a República Velha dá lugar a chamada Era Vargas, um novo processo se iniciaria no campo de atuação desses profissionais. Em 1937, com a implantação do Estado Novo, por Getúlio Vargas, o mercado se expandia para a arquitetura. O governo passa a promover obras simbólicas e via na Arquitetura Moderna um meio de alcançar o progresso tão almejado (SALVATORI, 2008).

Entre as décadas de 40 e 70, destacam-se os projetos desenvolvimentistas dos governos latino americanos. Após a Segunda Guerra Mundial os Estados Unidos se consolidam como potência econômica mundial e os países europeus procuram se reerguer. Aos países latino americanos, regidos por ditaduras, coube o título de subdesenvolvidos. Logo, os governos desses países buscariam cada vez mais o progresso, e veriam na arquitetura moderna um meio para isso. No cenário brasileiro destacaram-se nesse período, Lúcio Costa, Carmem Portinho, Affonso Eduardo Reidy, Oscar Niemeyer e Lina Bo Bardi (LIMA, 2012).

De acordo com Salvatori (2008), a Associação Brasileira de Ensino de Arquitetura - ABEA (2003), afirma que em 1933 havia no Brasil quatro escolas de Arquitetura. $\mathrm{O}$ ano em questão foi da regulamentação da profissão no país, os cursos estavam distribuídos no território nacional: no Rio de Janeiro, na ENBA; em São Paulo, na Escola Politécnica e na Escola de Engenharia do Mackenzie; e, por último, na Universidade de Minas Gerais, criada em 1930.

Na década de 1950, segundo Lima (2012), há um amadurecimento da arquitetura moderna latino americana. Era a década de Lúcio Costa, Affonso Eduardo Reidy e Oscar Niemeyer, adquirindo fama internacional. Na década posterior, de 1960, surgem projetos de grande plasticidade. É neste período 
que Carmen Portinho juntamente com seu marido Affonso Eduardo Reidy projetou o Museu de Arte Moderna (MAM) no Rio de Janeiro; e Lina Bo Bardi, o MASP, em São Paulo. Fato curioso sobre Carmen, que trabalhou atuante na luta militante feminista, é que ela participou na organização do movimento sufragista no Brasil, e chegou mesmo a propor às mulheres que não adotassem os sobrenomes de seus maridos ao se casarem. Atitude que, para ela, demonstrava independência e resistência (FGV, 2011; LIMA, 2012).

Segundo Fontes e Medeiros (2015), é na década de 1960 que as mulheres passariam a atuar no mercado mais fortemente, de um modo geral, e no campo arquitetônico as produções teriam tido início. Aliado a isso a imprensa feminista discutia as desigualdades sociais e desvantagens femininas.

Salvatori (2008) atenta para o que ela chama de "feminização da Arquitetura", apontando para uma tendência cada vez maior de alunas nas salas de aula, em relação o número de homens. Essa tendência parece ser um fato generalizado no mundo ocidental. No ensino europeu o curso de arquitetura tem sido escolhido em sua maioria por mulheres (Salvatori, 2008). De acordo com Durand (1989, apud FONTES e MEDEIROS 2015, p. 27) o crescimento da presença feminina nos cursos de Arquitetura e Artes Visuais no Brasil ocorreu entre os anos 1950 e 1980. Para este autor essa escolarização feminina pode ser explicada de dois modos: a geração anterior já estava atuando em um mercado economicamente seguro, não precisando procurar estudo; ou, a geração posterior já tinha estudado nessas profissões. Portanto, as mulheres dessa geração possuíam maior liberdade para fazer suas escolhas (SALVATORI, 2008).

Atualmente, segundo o censo de 2012 realizado pelo Conselho de Arquitetura e Urbanismo do Brasil - CAU/BR, a população de arquitetos e urbanistas no Brasil é formada em sua maioria por mulheres com menos de 40 anos. Segundo o Conselho elas correspondem a $61 \%$ dos profissionais atuantes no país, e os homens por sua vez, 39\%. Entretanto, a predominância feminina se dá entre os arquitetos jovens: entre 20 e 25 anos as mulheres representam $78,3 \%$ contra $21,66 \%$ masculino; entre 41 e 50 anos a diferença 
cai para 57,4\% contra 42,60\% dos homens; ao passo que acima dos 61 os homens chegam aos $71 \%$ dos profissionais em atividade e as mulheres $28,73 \%$.

O número de arquitetas e urbanistas no estado de Minas Gerais é de 4.564, o número masculino é de 2.281. Ou seja, o percentual feminino corresponde a $66,68 \%$ e o masculino a $33,32 \%$.

Fontes e Medeiros (2015) trazem à luz o fato de que as mulheres podem até representar uma maior porcentagem na profissão, mas não ocupam cargos de chefia e nem obtém o mesmo reconhecimento que os homens. Segundo ela, nas instituições como o Conselho de Arquitetura e Urbanismo do Brasil (CAU), Institutos de Arquitetos do Brasil (IAB) e Associação Brasileira de Ensino de Arquitetura e Urbanismo (ABEA), possuíam até o ano de 2015 diretores homens. Atualmente, no ano de 2016, o CAU e a IAB ainda contam com homens na presidência da diretoria, já ABEA possui uma mulher na presidência. (FONTES e MEDEIROS, 2015).

\section{Considerações finais}

Inicialmente levantamos os aspectos pertinentes à presença feminina na Arquitetura e, a partir desses apontamentos, percebemos que essa presença esteve vinculada a um papel social destinado à mulher. De forma mais específica, nos séculos XIX e XX, a questão de gênero esteve no cerne da constituição da própria área de conhecimento da Arquitetura e, pode-se dizer, a participação feminina se dá imersa na própria diferença de gênero que emerge das práticas sociais vigentes, sejam elas relativas ao contexto brasileiro, europeu ou norte-americano. É claro que não podemos desconsiderar que tais diferenças de gênero serão expressas cotidianamente de maneira singular em cada um desses cenários.

Num segundo momento, pensando em termos de um contexto nacional específico do século XIX, identificamos que os primeiros cursos de arquitetura surgiram a partir da Missão Francesa que, por interesse tanto por parte dos franceses como dos portugueses, disseminou um ensino classicizante no Brasil. A criação da Academia Imperial de Belas Artes saiu tardiamente do 
papel, levando dez anos para efetivamente funcionar, devido a conflitos por parte dos idealizadores. Entretanto, percebe-se no decorrer do tempo, a criação de mais cursos de arquitetura pelo país, como o caso da Universidade de Minas de Gerais. Nesse cenário das décadas de 1930 a 1950, quando boa parte dos cursos superiores de arquitetura começam a despontar, cabe realçar o lento acesso de mulheres a essa formação. De acordo com dados levantados por Sá (2010, p. 45) na USP, em 1950 registrou-se apenas 15\% de presença feminina no curso de arquitetura e urbanismo. De fato, essa porcentagem só começa a crescer e se estabilizar a partir da década de 1970 quando parece ter ocorrido uma alteração significativa neste quadro (SÁ, 2010, p. 45).

Em um depoimento colhido no site do Conselho de Arquitetura e Urbanismo (CAU), temos a ilustração do contexto citado acima:

Para Valeska Peres Pinto, arquiteta e diretora da Associação Nacional de Transporte Público (ANTP), é visível a predominância das mulheres nos cursos de arquitetura. Formada na década de 1970, Valeska conta que as mulheres eram minoria em sua turma. Em 1983, quando começou a lecionar no Centro Universitário Belas Artes, o quadro havia mudado: a maioria da classe era composta por mulheres (RODRIGUES, 2012).

No que diz respeito ao mercado de trabalho, as hierarquias sociais parecem perdurar e em grandes empresas é comum que mulheres ganhem menos que os homens. Rodrigues (2012) traz outros depoimentos que enfatizam, para além da diferença salarial, a falta de flexibilidade no ambiente de trabalho e o comportamento machista de clientes e colegas de trabalho relatados pela entrevistada Tabitha Pontes.

Soma-se a essa realidade a necessidade de se deixar explícito nos acordos sindicais cláusulas contra a discriminação e assédio sexual, como testemunhou a Bertha Costa, presidente do Sindicato dos Arquitetos de São Paulo (SASP) entre 1996 e 1998. Contudo, é no canteiro de obras que a questão de gênero parece aflorar. O testemunho de Solange Martinhão demonstra a necessidade da mulher não se intimidar "ao exigir: vai 
desmanchar e fazer de novo. (...) tem de ser rígida!" (RODRIGUES, 2012). Até mesmo na hora de receber as mulheres têm mais dificuldade, conforme indicou Rodrigues (2012), a partir do depoimento da arquiteta Monica Drucker: "Os clientes negociam mais seriamente com um rapaz porque ainda existe machismo, por incrível que pareça" (RODRIGUES, 2012).

Embora Rodrigues (2012) não explicite o mercado de trabalho onde as arquitetas acima transitam é evidente que não se trata de casos pontuais. Pelo contrário, são casos ilustrativos das inúmeras dificuldades que as arquitetas enfrentam no seu dia-a-dia. Talvez o mais curioso dessa dificuldade seja o comportamento inicial afirmativo de que inexiste discriminação e que não há impedimentos explícitos para as mulheres na Arquitetura.

Em síntese, a formação em arquitetura implica na apreensão dos espaços, tanto internos quanto externos, e requer habilidades na designação de função e formas de objetos que se relacionam com os mais diversos contextos. Ela expressa em projetos e nos variados designers as relações sociais que se encontram nos subterrâneos de cada sociedade. Enfim, as dificuldades e desafios que ainda existem tanto na formação quanto no mercado de trabalho para as arquitetas nada mais são que as expressões concretas de uma Arquitetura moldada ainda pelo olhar de uma sociedade com forte colorido patriarcal, apesar dos avanços vivenciados nas últimas décadas. Entretanto, cabe o alerta para adensarmos a discussão atual sobre gênero, visto que é premente repensar os espaços internos e externos através dos quais circulamos. Eles devem ser desnaturalizados não só porque ainda são pensados a partir do olhar masculino, mas, pelo fato de incorporarem em sua essência uma discriminação de gênero.

\section{Referências}

ARAÚJO, Anete. Estudos de gênero em arquitetura: um novo referencial teórico para a reflexão crítica sobre o espaço residencial. Cadernos PPG$A U / U F B A$. v. 5, n. 1 (2006). 
ARQUITETAS invisíveis. As mulheres. 2015. Disponível em: <http://www.arquitetasinvisiveis.com/as-mulheres>. Acesso em 16 nov. 2016.

ARQUITETURA e urbanidades. Bauhaus e sua arquitetura. 2011. Disponível em: <https://arquiteturaseurbanidades.wordpress.com/2011/04/24/> Acesso em: 16 nov. 2016.

CAVALCANTE, Elizabeth Cristina Tenreiro, DERNTI, Maria Fernanda e PALAZZO, Pedro Paulo. Os espaços urbano e privado e o controle da mulher colonial no século XIX. Arquitetas Invisíveis: pioneiras, v.1, p. 80-83, 2015.

COELHO, Luiza Rego Dias, SOLÉ, Julia Mazzutti Bastian e ALIAGA, Maribel. Em busca das pioneiras: uma breve história da mulher na arquitetura. Arquitetas Invisíveis: pioneiras, v.1, p. 50-53, 2015.

FONTES, Marina Lima de; MEDEIROS, Ana Elisabete de Almeida. Mulheres na arquitetura: reflexões sobre a inserção das mulheres no campo arquitetônico brasileiro. Arquitetas Invisíveis: pioneiras, v.1, p. 25-28, 2015.

FUNDAÇÃO GETÚlIO VARGAS, FGV. Carmen Portinho. Dicionário Histórico Biográfico Brasileiro pós 1930. 2ª ed. Rio de Janeiro: Ed. FGV, 2001. Disponível em: $<$ https://cpdoc.fgv.br/producao/dossies/JK/biografias/carmen portinho $>$.

Acesso em: 16 nov. 2016.

LIMA, Ana Gabriela Godinho. Arquitetas e Arquitetura na América Latina do Século XX. São Paulo: Altamira, 2012. E-book. ISBN 978-85-99518-16-8. Disponível em: $<$ https://femininoeplural.wordpress.com/2014/03/28/arquitetas-earquitetura-na-america-latina-do-seculo-xx/>. Acesso em: 24 out. 2016.

LIMA, Ana Gabriela Godinho. Revendo a história da arquitetura: uma perspectiva feminista. In: Congresso Luso-Brasileiro de História da Educação: percursos e desafios da pesquisa e do ensino de História da Educação. 2006, Uberlândia: Anais...Uberlândia: Universidade Federal de Uberlândia, 2006. p. 1479-1489.

MACHADO, Susete Marisa Fernandes. $O$ espaço das mulheres na arquitectura. 2011. 324 f. Dissertação (Mestrado Integrado em Arquitectura e Urbanismo) - Escola Superior Gallaecia, Vila Nova de Cerveira, Portugal. 2011.

MIGUEL, Jorge Marão Carnielo. Casa e lar: a essência da arquitetura. Vitruvius: Arquitextos, 029.11, ano 03, out 2002. Disponível em: $<$ http://www.vitruvius.com.br/revistas/read/arquitextos/03.029/746>. Acesso em: 13 nov. 2016. 
MONTANER, Josep Maria e MUXÍ, Zaida. Alternativas. In: Arquitetura e Política: ensaios para mundos alternativos. São Paulo: Gustavo Gili, 2014. $253 \mathrm{p}$.

MUMFORD, Lewis. A cidade na história: suas origens, transformações e perspectivas. São Paulo: Martins Fontes, 1998. 741 p.

OLIVEIRA, Gilberto R. de e MONT'ALVÃO, Claudia. A cozinha: espaço em permanente evolução. In: A evolução projetual de cozinhas residenciais - o papel e a importância da atuação do designer de produto. In: CONGRESO BRASILEIRO DE PESQUISA E DESENVOLVIMENTO EM DESIGN, 10, São Paulo, Anais. São Paulo: P\&D, 2010.p 1-10. Disponível em $<$ http://docplayer.com.br/8489755-3-a-cozinha-espaco-em-permanenteevolucao-3.html>. Acesso em: 13 nov. 2016.

RODRIGUES, José Wasth. Documentário arquitetônico relativo à antiga construção civil no Brasil. $5^{\mathrm{a}}$ ed. Belo Horizonte: Itatiaiai; São Paulo: Ed. da Universidade de São Paulo, 1979.

ROLNIK, Raquel. Lar, doce Lar: a história de uma fórmula arquitetônica. AU. Arquitetura e Urbanismo, São Paulo, v. ano 1, n. 3, 1985.

SÁ, Flávia Carvalho de. Profissão: arquiteta. Formação profissional, mercado de trabalho e projeto arquitetônico na perspectiva das relações de gênero. 196 p.: il. Dissertação (Mestrado) - Área de Concentração: Tecnologia da Arquitetura, FAUUSP, São Paulo, 2010.

SALVATORI, Elena. Arquitetura no Brasil. ensino e profissão. Arquiteturarevista, v. 4, p. 52-57, 2008.

SCHETTINO, Patrícia Thomé Junqueira. A mulher e a casa: estudo sobre a relação entre as transformações da arquitetura residencial e a evolução do papel feminino na sociedade carioca no final do século XIX e início do século XX. 2012. 323 f. Tese (Doutorado em Arquitetura e Urbanismo) - Programa de Pós-graduação em Arquitetura e Urbanismo da Escola de Arquitetura, Universidade Federal de Minas Gerais. Belo Horizonte, 2012.

Recebido em fevereiro de 2019. Aprovado em abril de 2019. 